\title{
Rethinking Photojournalism \\ The Changing Work Practices and Professionalism of Photojournalists in the Digital Age
}

\author{
Jenni Mäenpää
}

\begin{abstract}
Public service, ethics, objectivity, autonomy and immediacy are still often considered the core values of professional journalism. However, photojournalistic work has confronted historic changes since the advent of digitalization in the late 1980s. Professional photojournalists have been caught manipulating news images, video production has become a major part of news photographers' work, and newspapers freely publish photographs and videos taken by the general public.

The present article examines how news photographers negotiate these changes in photojournalistic work practices, and how they define their professional ambitions in the digital age. Photojournalists' articulations of professionalism are approached in relation to three digital innovations in photojournalism: digital photo editing, video production and user-generated images in newspapers. The empirical data consist of an online survey of and interviews with photojournalists in Finland. In the final analysis, it is suggested that the core ideals of photojournalism have to be renegotiated, because the work environment has changed drastically.
\end{abstract}

Keywords: photojournalism, news photographers, professionalism, digital photo editing, online news videos, amateur photography.

\section{Introduction}

In my opinion, a RAW file has nothing to do with reality, and I do not think you can judge the finished images and the use of Photoshop by looking at the RAW file.

(Danish photojournalist Klavs Bo Christensen, April 13, 2009)

This argument was made by a Danish photojournalist after he had been disqualified from a Picture of the Year contest because contest officials had determined that his image manipulation went too far. The decision was made by the competition judges after they had requested and seen a photographer's original RAW files on a story he submitted about Haiti (Winslow 2009). Along with the job losses that are a result of amateur photography ${ }^{1}$, these are examples of the revolution that photojournalism has confronted in the digital age. Many changes have followed a development that started in the 1990s, when the traditional darkrooms were taken over by computerized photo editing, after which the old film cameras were replaced by digital cameras. Furthermore, this development shifted photographers more into the role of office workers than of craftsmen, which they had considered themselves to be until that time. 
My hypothesis is that photojournalists of today have to reconsider their professional values when they are faced with fundamental changes in the work environment. According to Deuze (2005), the key values often associated with the ideology of journalism in elective democracies are public service, ethics, objectivity, autonomy and immediacy. Those values constitute the ways in which journalists fulfil their commitment to public service. This is closely tied to the notion of journalists being neutral, objective, fair and thus credible information providers for their audiences (ibid. 447).

Within photojournalism, the objectivity ideal is particularly strong. This may be explained by the special cultural status that photographs carry in modern society. Representing the outside world through photographs has the potential to be more precise than doing so through any other medium. Photographic images also have a long history of being used as evidence, even though, as Gunning (2004: 42) points out, there will always be motivation to counterfeit. For these reasons, photographs have been seen as ideal tools for news work that needs evidence to support the objectivity claim.

However, it is evident that the profession's old foundation, which was justified by the objective mediation of information, is being undermined in today's business-oriented environment. Various scholars have suggested that the objectivity norm within journalism is outdated, unattainable and undesirable (Boudana 2011; Muños-Torres 2012; Wien 2005). In addition, objectivity has already been widely replaced by professional subjectivity in the field of journalism (Salgado \& Strömbäck 2011). Thus, professional journalists have to redefine their tasks. One solution, suggested by Pietilä (2012: 257258 ), is that journalists once again bring the public into the craft, after it was exiled by journalism's insistence on objectivity. In practice, this could mean, for example, grassroots journalism that covers issues related to people's own lives, from the bottom up.

The aim of the present article is to examine what kind of professional values are articulated by photojournalists in the digital age. These values reflect the professional identity of photojournalists. This professional identity is observed in the way they understand and articulate themselves in relation to their work, and in the way they express what they want to become through their work (Eteläpelto \& Vähäsantanen 2006: 26; Wiik 2010: 58). To show the changing core values of the profession, I shall concentrate on three major changes in photojournalistic work. Digital photo editing, online news videos and nonprofessional photography are scrutinized through two different empirical data sets gathered through an online survey and interviews in Finland. Hence, the article contributes to the discussion of professional ideals within photojournalism after digitalization and is concerned with two questions:

RQ1. How do photojournalists articulate their professional values in the digital age?

RQ2. What is the relationship between professional values and digital photo editing, online news videos and amateur photography?

\section{Photojournalists and Professionalism}

Many scholars have debated whether journalism is a profession or a craft (Deuze 2005; Singer 2007). The occupation does not fulfil the criteria of more traditional professions, such as law and medicine, but journalism nevertheless has many professional characteristics, such as commitment to public service and professional ethics. Consequently, 
many media scholars have considered journalism a semi-profession, mostly because it is not possible to exclude amateurs from the field (Nygren \& Degtereva \& Pavlikova 2010: 115). Deuze (2005) has approached the journalistic occupation as an ideology rather than conceptualizing it as a profession. This primarily implies understanding journalism in terms of how journalists give meaning to their work. In this view, the professional identity of journalists is kept together by an occupational ideology of journalism. In the following section, I will discuss some aspects of the ideological values of public service, ethics, objectivity, autonomy and immediacy in relation to today's photojournalism.

In elective democracies, the ideology of journalism has historically been based on the public service ideal. Journalists share a sense of 'doing it for the public', of working as some kind of representative watchdog of the status quo in the name of the people, who buy their services (ibid. 447). For photojournalists this means, for example, transmitting honest and ethical news images for their audiences. In addition, new practices such as digital photo editing, fast online publication of photographs and videos and the use of amateur images are often justified by better public service.

On the other hand, some photojournalists see the quality of photojournalism being threatened, which deteriorates the idea of public service. This is because professional photographers believe they are consciously working to engage with readers, while the amateurs are just documenting an occurrence (Andén-Papadopoulos \& Pantti 2013: 967).

The sense of ethics, both institutional ethics and photographer-centric ethics, is strong among photojournalists. However, besides the general codes of conduct usually agreed to by national journalist associations, there is no common set of ethical guidelines especially for photojournalists, nor are there standard sanctions for ethical violations. Each news organization sets its own ethical standards. In particular, photo editing is an area where the number of ethical guidelines from different media organizations has increased in recent years. The strong emphasis on ethics is evidenced in the way news organizations handle certain violations of photojournalism ethics. Well-known examples would include, for example, the news agency Reuters and the Los Angeles Times, news organizations that have fired photojournalists for unethical photo editing. After such an incident at Reuters, definitive guidelines were published for Reuters photographers in 2007 (Schlesinger 2007). On the other hand, photographers seem to commit themselves to ethical standards of photo editing in a stronger way than any other occupational group working in newsrooms (Mäenpää \& Seppänen 2010: 460).

Photojournalism ethics are closely linked to the value of objectivity, which in the context of news photography is often synonymous with the credibility and evidential value of news images. Hence, the terms iconicity and indexicality, rooted in the study of semiotics, have often been used in defining a photograph and its evidential value. The first refers to the resemblance between the photograph and its referent, whereas the latter suggests that there is a physical connection between the two. Photographs have both of these characteristics. Photographs resemble the objects photographed and, moreover, photographs are caused by the radiated light from the object, which creates the physical connection. However, the notion of photographic indexicality has been highly debated, especially after digitalization (Cubby 2010; Doane 2008; Gunning 2004; Lister 2007). Furthermore, Åker (2012) argues that it is important to separate photographs from photography's indexical status as facts in journalism. According to him, photographic realism is instead a cultural construction that is turned into nature by written journalis- 
tic texts (ibid. 327-328). Still, photojournalists are very eager to advocate the ideal of objectivity. For example, in the digital age they are renegotiating the limits of digital photo editing by referring to practices that were traditionally done in darkrooms with film editing (Mäenpää \& Seppänen 2010: 471).

The value of autonomy, which usually refers to free and independent work by journalists, is faced with external pressures, as in the context of amateur news photography. Amateurs step into the field of professionals and challenge their monopoly over photojournalism. For professionals, one solution for maintaining autonomy has been to strengthen their gatekeeping role (Singer 2010). However, professionals also have other strategies regarding the use of citizen eyewitness images, such as seeing the amateur material as a resource to enhance the professional public service role (AndénPapadopoulos \& Pantti 2013).

Furthermore, internal pressures, such as the above-mentioned increased self-regulation, in visual decisions may lessen the control that individual photojournalists have over their own work. On the other hand, self-regulation strengthens their professional status. By following the norms commonly agreed upon in the field, photojournalists are able to stand out as professionals, in comparison to amateurs.

The work of journalists also involves notions of speed, fast decision-making, hastiness and working in accelerated real time (Deuze 2005: 449). The notion of immediacy, referring to the need to publish photographs and videos immediately after something newsworthy happens, has revolutionized the concept of time within photojournalism. Real-time reporting is considered highly important, even though it often requires balancing the values of immediacy and objectivity, which may lead to stretching traditional practices. For example, photo-editing decisions have to be made faster now. These decisions are negotiated by photojournalists in their daily work practices in a grey zone where the rules of conduct may sometimes be very obscure and unarticulated. Hence, photographers rely heavily on their own sense of ethics in their visual decisions (Mäenpää \& Seppänen 2010).

In addition, the pressure for instant publication in a continuous news cycle has diminished the authority of any one outlet to play a gatekeeper role for published information (Singer 2005: 179). This is probably most evident in the context of amateur news images, where professionals admit there is a problem with unverified visuals (Andén-Papadopoulos \& Pantti 2013: 969). These findings parallel the results of Peer and Ksiazek's (2011) study, where they compared YouTube videos to broadcast news. They found that most YouTube news videos adhere to traditional production practices such as editing techniques and audio quality, but break from common content standards such as the use of sources and fairness. Furthermore, these more relaxed content practices were rewarded with a higher number of views. Consequently, they suggest that the growing popularity of online news videos may be contributing to a breakdown of established standards in traditional media (ibid. 56).

\section{Empirical Material and Methods}

The data used in the present article have been collected from two earlier and separate research projects conducted in Finland. These versatile data bring out new information concerning the professional values of photojournalism, concentrating on the three major 
changes in the work environment, even though professional aspects were not explicitly articulated during data gathering. Hence, the qualitative material of the two data sets has been reanalysed from a new angle for the purposes of the article.

The first data set (later referred to as Data 1) consists of an online survey about the limits of digital photo editing. The study was carried out in 2007-2008, when the survey was sent to 362 professionals from 32 newspapers and 19 magazines. The final outcome was 182 respondents, which makes the response rate 50 percent. The respondents were strategically sampled to get a representative sample of different types of newspapers and magazines and geographical distribution, as well as an even distribution among occupational groups among the editorial staff. The survey involved a representative sample of respondents, including photojournalists, photo editors, photo department managers, art directors, graphic designers, layout editors, journalists and photo-editing staff ${ }^{2}$.

The survey consisted of 14 pairs of unaltered and altered images that were produced solely for the research project. The aim was to find out whether the respondent would accept the changes if the image was used as a news, reportage, feature or illustration photo. The images were shown as pairs of original and altered versions. With each pair of images, there was also a brief explanation of the alteration. The respondents also had an option to comment on their answers in free text fields. Along with the image pairs, there was an additional set of questions regarding the use of various editing techniques and decision-making in the editorial office (for more details, see Mäenpää \& Seppänen 2010).

The second data set (Data 2) consists of 20 interviews with photojournalism professionals from 10 newspapers. They were interviewed about their respective newspapers' online video production in 2008 to 2009 . The interviewees represented the biggest daily regional newspapers, in addition to one local and one financial newspaper in Finland. From each newspaper, one photographer or videographer and one manager were interviewed.

By using structured thematic questions, the study aimed to shed light on the work process, as well as the extent and the future goals of the newspaper's video production. The journalistic content and news criteria of the video production, as well as the nonprofessional contributions, were also emphasized in the interviews (Mäenpää \& Männistö 2009).

For the present article, the above-mentioned materials were analysed by focusing on photojournalism professionalism. All relevant citations and comments were gathered from the interviews and surveys, and the conclusions introduced here are the result of a close reading of this material. A thematic analysis was used to separate similar respondent comments, which were then analysed for the relevance of professional norms and values.

\section{Digital Photo Editing}

Photo editing is an inseparable part of photography in the digital age. Cropping, burning and dodging have become commonplace in darkrooms, but photo editing is now more than ever being reserved for computers. Even though the basic procedures have nothing to do with photo manipulation, an overall suspicion usually surrounds all photo editing in general. The challenge is to maintain the credibility of a practice at a time when it is often heavily contested. 
In the case of news photo editing, the issue of professional ethics becomes especially crucial. Photographers' references to professional status and skills can be seen as one coping mechanism in situations where they are asked to explain doubts about, for example, photographic reality. Furthermore, photojournalists aim to identify themselves as professionals of visual journalism, separate from other professionals in the newsroom and also from amateurs, who are not trained and are therefore not justified in making journalistic decisions (Williams et al. 2011: 86).

It seems to me that people who don't really understand photo editing are the ones who talk about these ethical problems. Every professional needs to understand the limits in this sense. Removing an object from an image is a totally different thing from a curves adjustment, for example. But the truth is always subjective. (Survey respondent No. 23, photographer, Data 1)

The last sentence of the citation claims that photographic truth is subjective in nature. By stating this, the respondent is referring to the fact that photography is subject to many choices made by the photographer. In this sense, news photography is far from technical recording, which is the category in which it has often been placed in the history of photojournalism (Zelizer 1995). In fact, published news photographs are the results of many journalistic decisions made by professionals, who have engaged themselves with mediating images that do not lie. Paradoxically, news photographs are valued as neutral records at the same time that they are admired as carefully crafted pictures (Schwartz 1992: 107).

This paradoxical tension puts pressure on the professionals, as they feel responsible for guaranteeing the credibility of news images. According to Fetveit (1999: 799-800), the credibility of visual representations has begun to rely more on individuals and institutions in the digital age, at a time when possibilities for digitally enhancing images are very extensive. The emphasis has therefore moved from technology towards institutions and individuals (ibid. 794). To cope with this pressure, photojournalists commonly use a rule of thumb: "the darkroom principle", which originated in the analogue photography period.

My own ethics are based on cropping and lighting, and everything one can do within the so-called traditional darkroom work. (Survey respondent No. 63, photographing journalist, Data 1)

In other words, the photo editing that was allowed in traditional darkrooms should also be allowed in digital editing. This is one strategy that sets limits on photo editing and allows photojournalism to maintain its objective status in the new digital environment (Mäenpää \& Seppänen 2010: 471; Kobré 2004: 332).

In the context of photojournalism, professional skills as one characteristic of professionalism could mean that the photographer has mastered the technology and is able to create images that do not require heavy editing.

Photographs taken by a professional photographer do not need such excessive editing. (Survey respondent 157, photo editor, Data 1)

Respondents preferred that all possible and relevant adjustments be made before or at the moment of releasing the shutter on the camera and not afterwards on a computer. This includes, for example, choosing the right lighting, lens and focal length for the 
exposure. This emphasis on editing skills also points to photojournalists' desire to be distinguished as professionals.

As for professional ethics, there seems to be a consensus among the surveyed professionals that some degree of common guidelines is needed for photo editing. However, it was found that chief editors and other managers are most willing to accept guidelines, whereas photographers and photo-editing staff are most reluctant to do so. One could argue that photojournalists, who are closer to photo editing in their daily work, rely more on their own professional ethics than on common guidelines, whereas managers would prefer to have guidelines to support their own decision-making (Mäenpää \& Seppänen, 2010: 6-7). Many of the respondents also emphasized that photo editing is part of creative work and that strict rules are therefore not suitable for it.

Guidelines would feel paternalistic.... I trust that the professionals master their field - ethically as well. (Survey respondent No. 140, photo editor, Data 1)

\section{Online News Videos}

One major turning point in photojournalistic work occurred during the period 2000-2006, when newspapers in Europe and the United States began producing video material. This has meant a dramatic change for news photographers, who have suddenly become video journalists as well. According to the interviews, there were divisions among photographers regarding how they reacted and adapted to this new form of expression in their daily work. This is closely connected to the question of how they identified themselves as photojournalists in the first place. While some were enthusiastic about the possibility of broadening their skills and finding more scope in their work, almost all the interviewed photographers had doubts about mastering both forms at once (also Singer 2004: 11). Also, some photographers clearly still identified themselves as photographers and did not want to work with moving images.

I'm a good and ambitious photographer, and I cannot shoot videos. ... I photograph in a communicative fashion, which would sound stupid on a video. As for me, I'll let the others shoot the videos, and I'll continue to do what I'm good at. (Respondent No. 6, photographer, Data 2)

Some interviewees were more positive, but they also said that it is difficult to master both still photography and video, and that it is even more challenging to combine the two during a single assignment. Hence, many photographers preferred specializing in one or the other discipline, rather than multi-skilling. In some cases, the photographers almost felt they were being forced to shoot videos, which made them feel that their professional autonomy was diminished.

On this issue, opinions were polarized between the photographers and their managers. Presumably, the managers were thinking primarily of cost efficiency for their organization, and for them multi-skilling seemed a more inviting option than seeking out trained specialists. The professional characteristics of a good videographer were listed by one interviewed manager at a newspaper's visual department:

A couple of our freelancers ... can produce an edited video clip to our server in half an hour when something important happens. In addition, they're able to take 
the still images together with the video. It means that they've learned a lot about the technical aspects of how it all works best. This is not just playing around but really professional work. (Interviewee No. 11, manager, Data 2)

One thing that was common to most of the interviewed photographers was their emphasis on the need for training to incorporate video into their daily work. Education and training were considered important in order to work ambitiously, but also to stand out as professionals in comparison to amateurs using video cameras. The lack of training was cited by photographers from many different organizations, and one of them even felt that sending professional still photographers to shoot videos without proper training is an affront to their professional identity.

The fact that still photographers shoot videos (without training) is a depreciation of the professionals. Think about, for example, how the photographers feel when news editors are shooting videos with mobile phone cameras. (Respondent No. 5, photographer, Data 2)

At the time of the interviews, the practices for making online videos were largely adopted from television production. This suggests that news photographers over time will begin to identify themselves to some extent as television cameramen. Borrowing practices from television production was seen as the easiest way to cope with these new circumstances.

We don't have the routines yet for making online videos, and therefore the television type of approach is the safest at the moment. (Interviewee No. 18, manager, Data 2)

Nevertheless, identifying as broadcast professionals was strictly rejected by some of the managers in the interviews. They want to see the newspaper business, even in the online context, as separate from television, and they did not believe it would be wise to position newspapers' online videos as being in competition with television news (also Bock 2008: 174).

The fact that online video production is still establishing its position in print newsrooms indicates that photographers are not bound to the long tradition of newspaper journalism when making online videos.

It's actually fun to shoot and edit the videos, since there are many more boring tasks that one could be doing. Since it is a new thing, there are no news criteria and many-decades-long traditions working as a burden. (Interviewee No. 19, manager, Data 2)

Meanwhile, many of the photographers discussed online videos somewhat dismissively or with a suggestion of embarrassment. The interviewees did not consider their video production to be very professional, as they had invested relatively few resources in it. Hence, some of the interviewees had conflicting feelings towards online video production: it is both inspiring and unprofessional. For the photojournalists, the notion of professional videos usually involved technical aspects such as steady shooting and quality audio. Furthermore, they expressed a strong intention to learn how to shoot and edit videos professionally and how to make their online videos appear professional (see Dickinson \& Bigi 2009 on television video journalists). 


\section{Amateur Photography}

Especially significant has been use of eyewitness material during disasters such as the 9/11 terrorist attacks on the United States in 2001, the South Asian tsunami in 2004, the London bombings in 2005, the earthquake in Haiti in 2010 and the Japan earthquake and tsunami in 2011 (Andén-Papadopoulos \& Pantti 2011: 14; Pantti \& Bakker 2009: 471). During those disasters, as well as others, the critical moments have often been captured by ordinary people witnessing important news events before professional photographers have arrived on the scene. In such cases, the amateur material may have a great deal of news value and will in some cases be published in television broadcasts and on newspapers' front pages.

This naturally puts the professionals into a new situation, as amateurs with values, intentions and ethics different from their own have suddenly entered their field. In fact, one could argue that this challenges the whole idea of professionalism that is based on specific knowledge, education and ethics. Similarly, Singer (2005: 178-180) has argued that some new media forms, including weblogs, are a major challenge to journalists and their role as gatekeeper, as well as to traditional practices. This was also outlined in the Finnish interviews. One manager emphasized, for example, professionals' increased responsibility in relation to audience material.

Media give the audience the forum and at the same time watch to see that there is no law breaking or vulgarity in the material. ... It is of course a positive phenomenon, but in the Internet environment source criticism is a challenge, since the decisions have to be made quickly. In my view, it demands a certain attitude and professional skills. (Interviewee No. 19, manager, Data 2)

The above citation reveals the twofold attitude towards amateur material that many media professionals have. On one hand, it is an opportunity to open the doors for citizens to participate in news making, which enriches news coverage and saves professional resources. On the other hand, it is viewed as a threat to the credibility of journalism and also to the professional identity of journalists, including photojournalists.

However, Pantti and Bakker (2009), among others, have found that journalists' reactions serve the purpose of maintaining the boundary between professional journalists and the general public. The traditional gatekeeping role of journalists is a strong one in terms of amateur images in news media. Pantti and Bakker suggest that use of nonprofessional images could create a true opportunity for professionals and amateurs to work together, as amateur images are the only consumer-created content that is occasionally given a status similar to that which professional material enjoys. However, these collaborations may be questionable because amateur visual material tends to be heavily screened in the news media (ibid. 485-486). More broadly, gatekeeping and control over decisionmaking in relation to audience material have also been noted in the research literature on participatory journalism as a whole (Domingo et al. 2008; Hermida \& Thurman 2008; Singer 2010; Williams et al. 2011).

It is nevertheless important to note that not all of the visual material provided by amateurs causes problems for photojournalists' sense of professional identity. Their professionalism may be challenged only by newsworthy images produced by the public. So-called 'hard news' material represents what newspapers are most actively seeking out, but it is seldom offered by amateurs. Instead of breaking-news images, the largest 
category of amateur images offered to the news media are 'soft' or non-news material such as everyday life content or nature and weather-related photography (Pantti \& Bakker 2009: 478). This is most often the case in local newspapers that do not even aim to cover national, let alone global, news events. At the local level, collaboration between the newspaper and citizens may strengthen the local community and citizens' commitment to the local news provider. However, in non-news situations, the gatekeeper role and the boundary between amateurs and professionals are still made very explicit by the professionals.

We are establishing a local YouTube for publishing citizen videos from, for example, local sports events. However, I consider it important that those be published on their own Web page in order to separate the journalistic content from the material produced by citizens. (Interviewee No. 1, chief editor, Data 2)

Because this statement emphasizes professionals' need to keep amateur content separate from journalistic content, it could also be interpreted as a certain ritual of transparency. For example, this kind of attitude allows media organizations to publish unverified material and meanwhile protect their professional authority (Karlsson 2010; Pantti \& Andén-Papadopoulos 2011). In other words, to restore the veracity of amateur material, journalists can impose the necessary frameworks or narratives on such amateurism and thus legitimize the content as journalistically relevant (Sjøvaag 2011: 84; on ethics and user-generated content, see also Ottosen \& Krumsvik 2012).

Even though protecting professional authority is considered important, some photojournalists are quite freely welcoming the use of amateur photography to complement their visual coverage and save professionals' time for more journalistically ambitious tasks.

I would be happy if most of the car accidents and coverage of local events would be taken care of by the audience material in the future. That would leave journalists more time to do their work professionally. (Interviewee No. 13, videographer, Data 2)

In his statement, the interviewee seems to be willing to assign quite crucial tasks to non-professionals, such as coverage of local events and accidents. However, in many cases the visual material from amateurs has special characteristics as compared to professional imagery. It possesses a certain feeling of authenticity and, in some cases, intimacy that is a consequence of the lack of elegance in non-professional images (Andén-Papadopoulos \& Pantti 2011: 12; Murray 2008: 160). An example was given by one newspaper's editor-in-chief:

Recently, we had an occasion at a local gas station, where a scooter was set on fire. One passer-by sent us a video of it. The quality of the material was very poor, but it attracted many viewers. It actually brings in the dramatic aspects, when the image is unfocused and moves back and forth. (Interviewee No. 1, chief editor, Data 2)

The strong reality effect of grainy and unfocused amateur images has even been used as a reason to prefer them over professional photography. This has led some news organizations to regularly search for newsworthy amateur images from photo blogs on the Internet (Pantti \& Bakker 2009: 482-483). Furthermore, many citizens, especially during disasters, have created photo-sharing groups on social media websites, such as 
Flickr, that allow members to store, sort, search and share photos via the Internet. It is now common for formal disaster-response agencies to request eyewitness photos. Mainstream media are already starting to use this material to their advantage with services like Yahoo!'s You Witness News and CNN's I-Report (Liu et al. 2008).

\section{Discussion}

Many of the changes in photojournalists' professional identity are occurring in the wider context of journalism in general. For example, the digitalization of journalistic texts, sound and images has made all journalistic content more vulnerable to copying, editing and sharing than ever before. Furthermore, the pressures of convergence affect other newsroom workers in addition to photojournalists (Avilés et al. 2004). Finally, all forms of user-generated content, including photographs, are utilized by the media in a variety of ways (Domingo et al. 2008).

By intentionally focusing on photojournalism, I have approached the work of photojournalists through three central changes that have become a part of their work since the advent of digitalization. Digital photo editing, newspapers' online video production and amateur photography have all played a role in reshaping photojournalists' professional identity. The questions proposed at the beginning of the present article were concerned with the way today's photojournalists see themselves in relation to their work. I have explored the concept of professional identity for photojournalists by looking at the journalistic ideological values listed by Deuze (2005) in relation to these three innovations in photojournalism.

My assumption when analysing the empirical data is that the professional values of photojournalists are constantly renegotiated in their daily work practices because their work environment has changed drastically. One clear example of the ongoing renegotiation of the professional values of objectivity and ethics is the practice of merging darkroom work methods with digital photo editing. Photojournalists have strongly identified themselves with the guaranteed trustworthiness of the images they produce. By referring to the old practices from the film period, they are able to maintain their "objective" status in the digital environment.

Photojournalists rely on their education, professional skills and ethical codes when they defend their decisions concerning, for example, photo editing or when they act as gatekeepers for amateur imagery published in newspapers. Many of these decisions are justified by their perceived public service role and their aim to engage with the audience. Meanwhile, they admit that truthfulness in photojournalism is subjective. Hence, we have a paradoxical tension between the subjective photojournalist and journalism's objectivity claim, a tension that influences the core of professional news photojournalism. In view of this, the photojournalist's tool, the camera, represents incorruptible objectivity, whereas the photojournalist as a human being may want to distort the 'facts' using his or her photographs. Professional ethics are therefore essential to photojournalistic professionalism, and photojournalists build their professional identity on their ethical integrity. Furthermore, they control the tension by creating new ethical codes of practice and by relying on certain ritualistic procedures that help maintain the status quo.

The value of the autonomous professional is also challenged in many ways in the digital age's converged newsrooms. For example, internal pressures regarding video pro- 
duction by newspapers are seen in the polarized opinions about multi-skilling expressed by photographers and their managers. Managers prefer multi-skilled staff, whereas the majority of photographers consider multi-skilling a threat to their professional identity. Forced to work with inadequate skills and time limits, professionals may seem like amateurs. This makes it impossible for them to be distinguished as professionals. Consequently, some photojournalists see their autonomy as having been weakened. Ultimately, it comes down to photojournalists' need to be autonomous and to tell the stories they want through photographs and videos (Deuze 2005; Singer 2004).

Real-time reporting in the continuous news cycle has affected the value of immediacy and created new practices, such as wider utilization of user-generated content. New services, such as the Swedish-based live video service Bambuser, are examples of this. It allows users to capture, share and watch live video through mobile phones and computers. This service is used by some media organizations, such as The Associated Press, and it was central in using video material from the Arab Spring, starting in 2010, and the war in Syria, since 2011. Regarding the verification of the material, the AP assures on its website that all video shared has been verified by social media specialists before being shared with a global audience via the worldwide network of its broadcasters. The AP therefore provides a fresh example of a reorientation in which traditional journalistic values such as autonomy and objectivity are merged with the contemporary networked society and the utilization of user-generated content. It seems that this reorientation is not contradictory to, but rather reshapes and complements traditional news values.

The article has suggested that a renegotiation of photojournalists' professional values is ongoing and inevitable in the changing media environment. Of course, the study has several limitations. The two data sets used were originally gathered for the purpose of studying newsroom practices rather than professional values. Nonetheless, this rich empirical material includes interesting evidence that suggests change in these professional values. The findings are also in line with what others have found (Andén-Papadopoulos \& Pantti 2013; Singer 2010; Singer 2007). More empirical research is needed to systematically explore the many factors that influence photojournalists' professional values.

\section{Notes}

1. For example CNN in 2011. www.mediabistro.com/tvnewser/dozens-of-jobs-cut-at-cnn-new-york-atlantawashington-dc-miami-la-staffers-pink-slipped_b97876 (Accessed Oct 17 ${ }^{\text {th }}$ 2013.)

2. Distribution of the occupational groups in the data 1: photographers and photographing reporters (25\%), managers (16\%), photo editing staff (15\%), journalists (15\%), chief editors $(11 \%)$, photo editors $(6 \%)$, graphic designers $(6 \%)$, art directors $(4 \%)$ and layout editors $(3 \%)$.

\section{References}

Åker, P. (2012) Photography, objectivity and the modern newspaper. Back to the artist. Journalism studies, 13(3): 325-339.

Andén-Papadopoulos, K. \& Pantti, M. (2013) Re-imagining crisis reporting: Professional ideology of journalists and citizen eyewitness images. Journalism, 14(7), 960-977.

Andén-Papadopoulos, K. \& Pantti, M., eds. (2011) Amateur images and global news. Bristol: Intellect.

Avilés, J.A. García \& León, B. \& Sanders, K. \& Harrison, J. (2004) Journalists at Digital Television Newsrooms in Britain and Spain: workflow and multi-skilling in a competitive environment. Journalism Studies, 5(1): 87-100.

Bock, M.A. (2008) Together in the Scrum. Practicing News Photography for Television, Print and Broadband. Visual Communication Quarterly, Vol. 15: 169-179. 
Boudana, S. (2011) A definition of journalistic objectivity as a performance. Media, Culture \& Society 33(3): 385-398.

Cubby, D. (2010) Within an illustrated box: ontology of a photography in demise. An extract from the exegesis Photography: the dominant aesthetic. Global Media Journal - Australian Edition, 4(2): 1-10.

Deuze, M. (2005) What is journalism? Professional identity and ideology of journalists reconsidered. Journalism 6(4): 442-464.

Dickinson, R. \& Bigi, H. (2009) The Swiss video journalist. Issues of agency and autonomy in news production. Journalism, 10(4): 509-526.

Doane, Mary Ann (2008) Indexicality and the concept of medium specificity. In Robin Kelsey \& Blake Stimson (eds.), The Meaning of Photography, Williamstown, Mass: Sterling and Francine Clark Art Institute.

Domingo, D. \& Quandt, T. \& Heinonen, A. \& Paulussen, S. \& Singer, J. \& Vujnovic, M. (2008) Participatory journalism practices in the media and beyond. An international comparative study of initiatives in online newspapers. Journalism Practice 2(3): 326-342.

Eteläpelto, A. \& Vähäsantanen, K. (2006) Ammatillinen identiteetti persoonallisena ja sosiaalisena konstruktiona. [Professional identity as a personal and social construction] In A. Eteläpelto \& J. Onnismaa (eds.) Ammatillisuus ja ammatillinen kasvu. [Professionality and professional growth.] Aikuiskasvatuksen 46. vuosikirja. Kansanvalistusseura ja Aikuiskasvatuksen Tutkimusseura. Vantaa.

Fetveit, A. (1999) Reality TV in the digital era: a paradox in visual culture? Media, Culture \& Society, Vol. 21: $787-804$.

Gunning, T. (2004) What's the Point of an Index? Or, Faking Photographs. Nordicom Review 1-2: 39-49.

Hermida, A. \& Thurman, N. (2008) A clash of cultures. The integration of user-generated content within professional journalistic frameworks at British newspaper websites. Journalism Practice, 2(3): 343-356.

Karlsson, M. (2010) Rituals of transparency. Evaluating online news outlets' uses of transparency rituals in the United States, United Kingdom and Sweden. Journalism Studies, 11(4): 535-545.

Kobré, K. (2004) Photojournalism: the Professional's Approach. Burlington: Focal Press.

Lister, M. (2007) A Sack in the Sand: Photography in the Age of Information. Convergence, 13(3): 251-274.

Liu, S.B. \& Palen, L. \& Sutton, J. \& Hughes, A.L. \& Vieweg, S. (2008) In Search of the Bigger Picture: The Emergent Role of On-Line Photo Sharing in Times of Disaster. In F. Fiedrich and B. van de Walle (eds.) Proceedings of the 5th International ISCRAM Conference - Washington, DC, USA, May 2008.

Muños-Torres, J.R. (2012) Truth and objectivity in journalism. Anatomy of an endless misunderstanding. Journalism Studies 13(4), 566-582.

Murray, S. (2008) Digital Images, Photo-Sharing, and Our Shifting Notions of Everyday Aesthetics. Journal of Visual Culture 7(2): 147-163.

Mäenpää, J. \& Männistö, A. (2009) Kun kaikki videoivat kaikkea. Liikkuva kuva sanomalehden sivuilla. [When all video all. Moving image in a newspaper.] Publications of the Department of Journalism and Mass Communication, Series B 53 / 2009, University of Tampere.

Mäenpää, J. \& Seppänen, J. (2010) Imaginary dark room. Digital photo editing as a strategic ritual. Journalism Practice 4(4): 454-475.

Nygren, G. \& Degtereva, E. \& Pavlikova, M. (2010) Tomorrow's Journalists. Trends in the development of the journalistic profession as seen by Swedish and Russian students. Nordicom Review 31(2): 113-133.

Ottosen, R. \& Krumsvik, A.H. (2012) Digital challenges on the Norwegian media scene. Nordicom Review 33(2): 43-55.

Pantti, M. \& Andén-Papadopoulos, K. (2011) Transparency and trustworthiness: Strategies for incorporating amateur photography into news discourse. In Andén-Papadopoulos, K. \& Pantti, M. (eds.), Amateur images and global news. Bristol: Intellect.

Pantti, M. \& Bakker, P. (2009) Misfortunes, memories and sunsets. Non-professional images in Dutch news media. International Journal of cultural studies 12(5): 471-489.

Peer, L. \& Ksiazek, T.B. (2011) YouTube and the challenge to journalism. New standards for news videos online. Journalism Studies, 12(1): 45-63.

Pietilä, K. (2012) Professional journalism: An intermediary social practice. In J. Herkman, T. Hujanen \& P. Oinonen (eds.) Intermediality and media change. Tampere: Tampere University Press.

Salgado, S. \& Strömbäck, J. (2011) Interpretive journalism: A review of concepts, operationalizations and key findings. Journalism 13(2): 144-161.

Schlesinger, D. (2007) The use of Photoshop. http://blogs.reuters.com/blog/archives/4327 (Accessed Oct. $17^{\text {th }} 2013$.)

Schwartz, D. (1992) To tell the truth: Codes of objectivity in photojournalism. Communication, Vol. 13: 95-109.

Singer, J.B. (2010) Quality control. Perceived effects of user-generated content on newsroom norms, values and routines. Journalism Practice, 4(2): 127-142.

Singer, J.B. (2007) Contested autonomy. Professional and popular claims on journalistic norms. Journalism Studies, 8(1): 79-95. 
Singer, J.B. (2005) The political J-blogger. 'Normalizing' a new media form to fit old norms and practices. Journalism, 6(2): 173-198.

Singer, J.B. (2004) Strange bedfellows? The diffusion of convergence in four news organizations. Journalism Studies 5(1): 3-18.

Sjøvaag, H. (2011) Amateur images and journalistic authority. In Andén-Papadopoulos, Kari \& Pantti, Mervi, (eds.), Amateur images and global news. Bristol: Intellect.

Zelizer, B. (1995) Words against images. Positioning newswork in the age of photography. In Hanno Hardt \& Bonnie Brennen (eds.), Newsworkers. Toward a history of the rank and file. Minneapolis: University of Minnesota Press.

Wien, C. (2005) Defining Objectivity within Journalism. An Overview. Nordicom Review 2/2005: 3-15.

Wiik, J. (2010) Journalism in Transition. The Professional Identity of Swedish Journalists. Doctoral Thesis. Department of Journalism, Media and Communication, University of Gothenburg, Sweden.

Williams, A. \& Wardle, C. \& Wahl-Jorgensen, K. (2011) “Have they got news for us?" Audience revolution or business as usual at the BBC? Journalism Practice, 5(1): 85-99.

Winslow, D.R. (2009) “Danish Photoshop Debate Leads To Disqualification”. News Photographer magazine. https://www.nppa.org/news/811 (Accessed Oct. 17 ${ }^{\text {th }}$ 2013).

JENNI MÄENPÄÄ, Ph.D. Student, School of Communication, Media and Theatre, University of Tampere, jenni.k.maenpaa@uta.fi. 